\title{
Utilidad de la radiografía de tórax en emergencia pediátrica, Hospital III Grau EsSalud
}

\author{
Usefulness of chest X-ray films in pediatric emergency, \\ EsSalud III Grau Hospital
}

Correspondencia Javier Miranda Candelario drjaviermirandac@hotmail.com

Recibido: 13/03/2017 Aprobado: 12/04/2017

Citar como: Miranda Candelario J, Mestanza Perea M, Campos Noriega C, Espino Huamán J, Cabrera Hipólito S, Miranda Cabrera B. Utilidad de la radiografía de tórax en emergencia pediátrica, Hospital III Grau EsSalud [carta]. Acta Med Peru. 2017;34(2):156-8

\author{
Javier Miranda Candelario1,a, Miguel Mestanza Perea1,b, Cecilia Campos \\ Noriega ${ }^{1, a}$, Javier Espino Huamán ${ }^{1, a}$, Segundo Cabrera Hipólito ${ }^{1, c}$, Bianca Miranda \\ Cabrera ${ }^{2, d}$ \\ 1 Hospital III de Emergencias Grau, EsSalud. Lima, Perú. \\ 2 Hospital Nacional Cayetano Heredia. Lima, Perú. \\ a Médico Pediatra, b Médico Residente III, c Médico Radiólogo, d Endocrinólogo Pediatra
}

\section{Sr. Editor:}

En las salas de emergencia hay ansiedad de los padres y de los médicos por llegar rápido a un diagnóstico correcto, lo cual lleva muchas veces a tomar acciones exageradas. Los estudios radiográficos son de vital ayuda en la atención en dichos servicios; sin embargo, se nota una "radiografomanía" que podría tener diversas causas. Por una parte, la presión externa, toda vez que los errores diagnósticos, especialmente en las enfermedades infecciosas, se encuentran entre las causas más comunes de demandas por negligencia en pediatría y por otro lado está el uso rutinario de esta prueba diagnóstica en patologías específicas, muchas veces sin un juicio previo.

Las radiaciones conllevan un riesgo potencial, sobre todo en niños. Se debe evitar exponerlos innecesariamente; se ha demostrado que un recién nacido es 10 a 15 veces más sensible a la radiación que un adulto ${ }^{[1]}$. Lo importante es optimizar las pruebas para obtener la máxima información con la mínima radiación. Ni siquiera las pequeñas dosis de radiación están totalmente exentas de riesgos. Una pequeña parte de las mutaciones genéticas y de las neoplasias malignas pueden atribuirse a esa radiación que tanto nos preocupa.

Realizamos un estudio retrospectivo y transversal durante los meses de mayo y junio del 2015 en la emergencia pediátrica del Hospital III de Emergencias Grau - EsSalud con la finalidad de determinar la asociación entre la neumonía radiológica y la neumonía clínica. Las radiografías de tórax (RT) solicitadas fueron revisadas por dos pediatras y un radiólogo, quienes las calificaron individualmente como neumonía radiológica (NR) o como no neumonía; las discrepancias las resolvieron por mutuo acuerdo, luego se obtuvieron los diagnósticos clínicos de los pacientes que correspondían a las radiografías revisadas.

Se realizó estadística descriptiva inferencial con SPSS; se buscó asociación entre NR y neumonía clínica con chi cuadrado y se determinó sensibilidad, especificidad, valores predictivos positivo (VPP) y negativo (VPN) de la RT. Se consideró estadísticamente significativo un $p<0,05$.

Se realizó análisis de partición recursiva para organizar el árbol de clasificación de las radiografías, con nodo CHAID, método que genera arboles de decisión mediante valores estadísticos de chi- cuadrado para identificar divisiones óptimas. 
Tabla 1. Frecuencia de neumonía radiológica según diagnóstico clínico de alta

\begin{tabular}{lcc} 
& \multicolumn{2}{c}{ Neumonía radiológica } \\
\cline { 2 - 3 } Diagnóstico de alta & \multicolumn{1}{c}{ Sí } & No \\
& $\mathbf{n}(\%)$ & $\mathbf{n}(\%)$ \\
SOBA & $7(7,4)$ & $87(92,6)$ \\
Asma & $5(9,2)$ & $49(90,8)$ \\
Síndrome febril & $2(6,0)$ & $31(94,0)$ \\
IVAS & $1(5,0)$ & $19(95,0)$ \\
Bronquiolitis & $2(12,5)$ & $14(87,5)$ \\
S. dolor abdominal & $0(0)$ & $13(100,0)$ \\
Apendicitis & $0(0)$ & $2(100,0)$ \\
SOBA + BNM & $15(51,7)$ & $14(48,3)$ \\
Neumonía & $7(87,5)$ & $1(12,5)$ \\
Asma + BNM & $2(66,6)$ & $1(33,4)$ \\
Total & $41(15,0)$ & $231(85,0)$ \\
\hline
\end{tabular}

SOBA: síndrome de obstrucción bronquial aguda; IVAS: infección de vías aéreas superiores; BNM: bronconeumonía.

De 315 RT tomadas durante el periodo de estudio, se revisaron 272; 139 (51\%) correspondieron a pacientes hospitalizados, de los cuales 39 (14\%) tuvieron el diagnóstico de neumonía.

Un total de $42 \%$ de las radiografías se tomaron a menores de un año; 30\%, al grupo de 2 a 5 años; 41 (15\%) radiografías fueron calificadas como NR y 231 (85\%) como normales. Hubo significancia estadística entre NR y grupo etario de 11 a 14 años, y entre NR y diagnóstico clínico de neumonía $(p=0,001$ y OR= 8); de esta relación RT, como prueba diagnóstica, tiene S $60 \%$, E 93\%, VPP 60\% y VPN 92\%; igualmente NR con hospitalización fue significativo $(p<0,001$ y $O R=5)$.

Los diagnósticos que requirieron RT se observan en la Tabla 1, en los primeros 7 hubo un exceso de radiografías.

En emergencia pediátrica predominaron enfermedades respiratorias con $68 \%$; sobre todo en menores de 3 años con $43 \%$. Encontramos que $72 \%$ de RT eran menores de 5 años.

El objetivo de la RT es la identificación de neumonía. En niños con signos de neumonía, la RT se indica ante la duda, sospecha de derrame pleural, no respuesta a antibióticos, o por evolución prolongada ${ }^{[2]}$. Cuando se justifique la RT, ésta no ha demostrado modificar la conducta clínica, ni el tiempo de recuperación ${ }^{[3]}$. Encontramos que aquellos niños con historia y examen compatible con neumonía presentaron 8 veces la probabilidad de presentar también una radiografía patológica. A mayor edad aumenta la posibilidad de identificar una NR ${ }^{[4]}$.

La mayoría de enfermedades respiratorias son de etiología viral y no requieren para el diagnóstico de estudios radiográficos.

Se indica RT en el síndrome obstructivo bronquial agudo solo ante alta sospecha de neumonía; encontramos que a 123 se les solicitó RT y solo 22 (18\%) tuvieron NR.

El diagnóstico de bronquiolitis es clínico y las RT no se deberían indicar rutinariamente, salvo curso inusual o presenten enfermedad grave, el $25 \%$ de los hospitalizados tendrán atelectasia ${ }^{[5,6]}$. En nuestra serie de 16 casos 2 (12\%) tenían NR.

En la crisis asmática no se recomienda RT salvo para detectar complicaciones, haya evolución atípica, u hospitalización en cuidados intensivos. No obstante, en nuestro estudio observamos que en el servicio de emergencia los niños regresaban con su radiografía bajo el brazo después de su última nebulización. De los 54 pacientes con crisis asmática a los que se tomó RT, solo 5 (9\%) tenían NR.

A 20 pacientes con infección de vías aéreas superiores se tomó RT y solo 1 tuvo NR.

En lactantes febriles sin foco se solicitará RT cuando $T^{\circ}>39^{\circ} \mathrm{Cy}$ hemograma con leucocitos $>15000^{[7]}$. A 33 con este diagnóstico se tomó RT y solo 2 (6\%) tuvieron NR.

En cuadros febriles asociados a dolor abdominal una RT, puede evidenciar neumonía basal como causa del dolor; de las 13 RT que se tomaron por dicha causa, ninguna fue positiva.

No existe justificación para RT prequirúrgico. No predice complicaciones respiratorias las cuales sí son previstas por el estado clínico del paciente, el tipo de anestesia, el estado nutricional y el tipo de cirugía; sin embargo, se sigue solicitando ${ }^{[8]}$.

La hospitalización es un factor de riesgo para indicar RT; en nuestro estudio 139 (51\%) fueron hospitalizados, 40 (15\%) tuvieron diagnóstico de neumonía.

Estos resultados sugieren un uso excesivo de un procedimiento potencialmente dañino. Si bien un estudio descriptivo y retrospectivo no permite generar conclusiones; este trabajo nos señala que, en el síndrome febril e infecciones de vías aéreas superiores, la clínica es más importante; en el grupo de síndrome de obstrucción bronquial y asma, se pueden restringir; y queda un grupo bien identificado en quienes se solicita RT.

Estos hallazgos ayudaran en el diseño de una guía de práctica clínica, para el uso de la RT.

Ante la duda, la evaluación y el seguimiento son la primera opción, antes que la obtención de una radiografía ${ }^{[9]}$. 


\section{REFERENCIAS BIBLIOGRÁFICAS}

1. Renedo de la Hoz S. Riesgos de la radiación en imágenes pediátricas. Neumol Pediátr. 2015;10(2):54-7.

2. Zenteno D, Girardi G, Fuentes L, Pérez A, González R, Abara S, et al. Utilidad de la radiografía de tórax en niños como aproximación a la etiología de neumonía adquirida en la comunidad. Rev Chil Infectol. 2008;25(1):17-21.

3. Tew J, Calenoff L, Berlin BS. Bacterial or nosocomial pneumonia: accuracy of radiographic diagnosis. Radiology. 1977;124(3):607-12.

4. Cincinnati Children's Hospital Medical Center. Community acquired pneumonia guideline team. Evidence-based care guidelines for medical management of community acquired pneumonia in children 60 days to 17 years of age [Internet]. Cincinnati: Cincinnati Children's Hospital Medical Center; c1999-2017 [citado el 22 de setiembre de 2011]. Disponible: www.cincinnatichildrens.org/svc/ alpha/h/health-policy/ev-based/pneumonia.htm
5. Knapp JF, Simon SD, Sharma V. Variation and trends in ED use of radiographs for asthma, bronchiolitis, and croup in children. Pediatrics. 2013;132(2):245-52.

6. Castillo Galván R, Cuello García CA. Radiografía de tórax: un recurso usualmente innecesario para el diagnóstico de bronquiolitis. Bol Med Hosp Infant Mex. 2011;68(3):213-20.

7. Bachur R, Perry H, Harper MB. Occult pneumonias: empiric chest radiographs in febrile children with leukocytosis. Ann Emerg Med. 1999; 33(2):166-73.

8. Blanco 0 , Iñon A. Consenso en la evaluación y preparación prequirúrgica en pediatría. Arch Arg Pediatr. 1998;96:413-31.

9. Predicción de neumonía en un departamento de emergencias pediátricas: Desarrollo de una guía de práctica clínica de neumonía en Emergencias. Buenos Aires: Inrtramed; 2011.

\section{Ahora puede enviar sus artículos para Acta Médica Peruana en nuestro Open Journal System:}

\section{www.amp.cmp.org.pe}

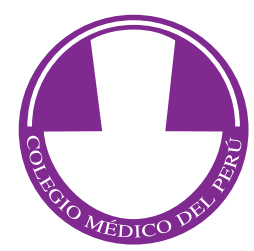

